Article

\title{
Evaluating Social Media Response to Urban Flood Disaster: Case Study on an East Asian City (Wuhan, China)
}

\author{
Xiaoxue Cheng, Guifeng Han *, Yifan Zhao and Lin Li
}

Key Laboratory of New Technology for Construction of Cities in Mountain Area of Education Ministry, Faculty of Architecture and Urban Planning, Chongqing University, Chongqing 400045, China; cxxcqu01@sina.com (X.C.); sitelatuosi@163.com (Y.Z.); 201715131111@cqu.edu.cn (L.L.)

* Correspondence: hangf@cqu.edu.cn

Received: 2 August 2019; Accepted: 24 September 2019; Published: 26 September 2019

\begin{abstract}
Social media is an important tool for disaster prevention and management. To reveal the public responses to disasters on social media in the context of East Asian culture, an urban flood disaster event that occurred in Wuhan City, China, in the summer of 2016 was selected as a case. Data were collected from Sina-Weibo, which is the earliest and most popular social media platform in China. We categorized a total of 17,047 messages into four types, analyzed the Pearson correlation between information dissemination and precipitation, and identified the important accounts and their messages in the social networks by visualized analysis. The results show that there is a one-day lag between participation and public response. Message dissemination has a steeply downward trend over time, that is, a long tail effect. Information disseminates quickly within two hours, and then dissemination declines after four hours, with opinion messages disseminating faster than other types of messages. Famous news organizations and several celebrities play a leading role in social networks. In general, the participation of Chinese netizens in disaster events is lower than that of people in Western countries, and social media is not yet used as a tool for disaster response.
\end{abstract}

Keywords: disaster; public response; social media; Sina-Weibo; flood event

\section{Introduction}

Social media refers to internet-based applications that enable people to communicate and share resources and information through conversation and interaction [1,2]. Thus far, Facebook is the most popular social media platform with 2.2 billion active users distributed across 119 countries worldwide, followed by Instagram with 600 million active users. Twitter is more popular in the United States and most Western European countries than other social media [3]. Social media has a large number of global users and a wide geographical distribution. Users can easily post, comment, and repost any message on social media, and it takes only a short time to obtain and share information. For these reasons, social media networks have emerged as a powerful tool in allowing the collaboration and sharing of information during times of disasters. As early as 2011, scholars began to pay attention to the use of social media during natural disasters. Yates \& Paquette (2011) presented how social media is used [4]; what influence it has on knowledge sharing, reuse, and decision-making; and how knowledge was effectively maintained in these systems during the Haitian earthquake. In addition, the Queensland floods that occurred in 2011 provided a unique opportunity to explore the information experiences of people using social media during the flooding in the Brisbane River [5]. Shortly afterward, with the increasing coverage of the internet, many social media platforms gradually came online. The public began to pay more attention to social media and participate more in social media than before. 
Accordingly, researches on the use of social media during various disasters have increased every year. The recent studies have demonstrated that social media is becoming a great means of crisis response [6-9]. Government department and emergency response agencies use social media platforms as communication channels [10], to publish believable information (updates, warnings, and briefs) [11], and eliminate rumors through centralized social media portals [12]. Functioning as an information bridge, nonprofits and hoc organizations post, share, find, provide information and resources [10,12], and encourage donations and volunteer actions via social media to and from response agencies and the public [13]. Opinion leaders (mayors, celebrities) play important roles when they eliminate rumors, reassure families of victims [14], and attract the public to engage in a topic through social media [6]. Social media is used by individuals to gather information [8], report on activities "on-the ground" [15], share emotions, and fulfill their needs and desires from others [12]. Even for disabled individuals, social media can be used to seek information [16], share information [12], and call for help.

Social media has been used at all phases of disaster preparedness [12,17-19], response, mitigation [12,20], and recovery [10]. During preparedness phase, meteorological warning departments use social media platforms to post early warning messages and provide a mechanism for individuals to participate in their own preparedness and safety [21]. When disasters occur, government agencies turn to social media platforms to manage crises and grief and to coordinate community-based response efforts $[22,23]$. Individuals begin to seek information from others and share information about event impacts [8,24-28]. As the disaster enters a mitigation phase, government agencies and social organizations begin to control rumors [10], provide donations [29], and volunteer services on social media [21,30]. During the recovery phase, government or social organizations post messages on social media to make longer term planning and offer assistance to restore the situation back to normalcy [22]. Effective disaster response relies on effective organizational communication to solve problems and disseminate relevant information [11]. The Virtual Social Media Working Group and Department of Homeland Security First Responders Group concluded that social media used as a tool by public safety agencies in recent disasters has eight functions: Information sharing (one-way), information sharing (two-way), situational awareness, misinformation management, decision-making, reconnection, donations, and volunteer management [29,31]. In fact, at each stage of a disaster, the attention paid to disaster events in social media is different. A complex network of relationships will form when information is posted or shared through one-way or two-way communication. At different stages of disasters (preparedness, response, mitigation, recovery), responders play different roles in response to disasters on social media $[10,18,32]$. Accordingly, the functions of social media vary at different stages (Figure 1).

Although there are some related studies, we found that most of them focus on disaster events in Western countries using data from several common social media platforms $[5,6,10,12,27,28,33]$. Yet, there are some differences between East Asian countries and the Western countries in terms of the ways of thinking, the concept of science, behavior, and collective or individual interests. All of these differences may lead to different public responses to disaster events.

As the largest country in East Asia, China has undergone rapid urban development in recent years. Artificial structures are increasing in cities, and the urban surface and water system are seriously affected. In recent years, the phrase "watching the sea in the city" (joking about floods in cities) has appeared on Chinese social media almost every summer, especially in large inland cities. Unlike earthquakes, landslides, droughts, and heat waves disasters, flood disasters gradually form after surface runoff exceeds the capacity of drainage systems in cities, which usually takes hours to several days, depending on rainfall. Obviously, there should be a time lag between the beginning of rainfall and widespread public response on social media. It would be very beneficial for flood prevention and mitigation if the responses of the public and government agencies on social media could be utilized effectively. However, there are very few relevant studies in China. Taking flood events in Wuhan City, China, in 2016 as an example, this study attempts to analyze the dissemination process of information and public responses to flood events on Sina-Weibo in Chinese internet environment. 


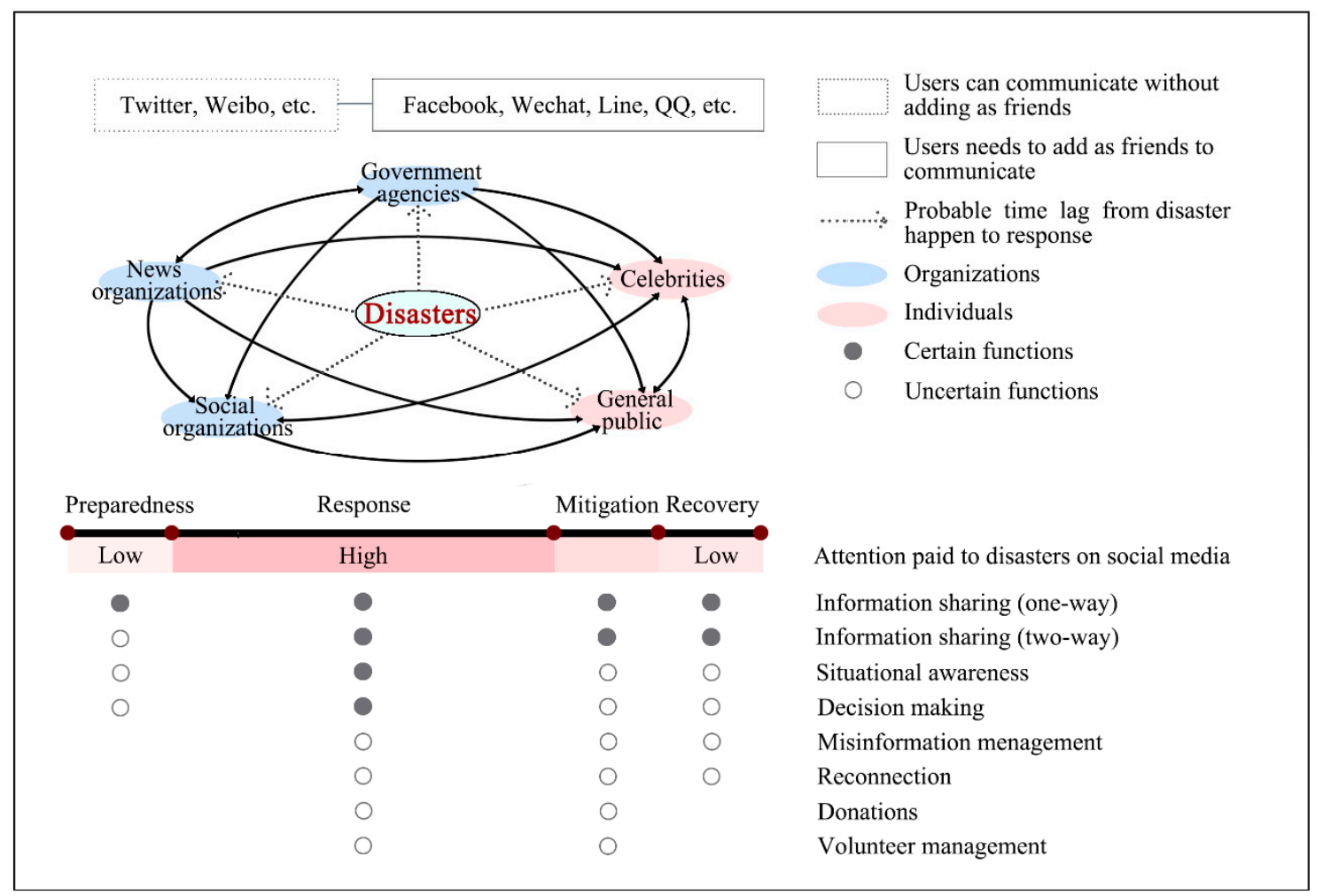

Figure 1. The role of social media in disaster preparedness, response, mitigation, and recovery.

This paper aims to (1) determine how well the social media (Sina-Weibo) has been used as a communication tool in urban flood disaster management, (2) determine how long the time lag is from the beginning of rainfall to widespread public response to flood events on Sina-Weibo, (3) identify which kind of message has the fastest dissemination speed and what message content has slow heat attenuation, and (4) explore which accounts play a leading role in the social media network during the flood event in the context of East Asian culture. In addition, we attempt to discuss the differences in information dissemination-related disaster events between Sina-Weibo and other social media platforms in Western countries.

\section{The Flood Event in Wuhan City in the Summer of 2016}

In July 2016, continuous heavy rainfall caused floods in 26 provinces along the middle and lower reaches of the Yangtze River in China. Among them, Wuhan City, the capital of Hubei Province, was the most affected area (Figure 2). From late June to early July 2016, precipitation reached 1036.4 millimeters in Wuhan City. The affected population reached 757 thousand people. 14 people died, 167,897 people were moved to safe areas, 2.36 thousand buildings were destroyed, and 370 buildings were damaged. The traffic system was paralyzed, schools closed, and railway stations were flooded. 

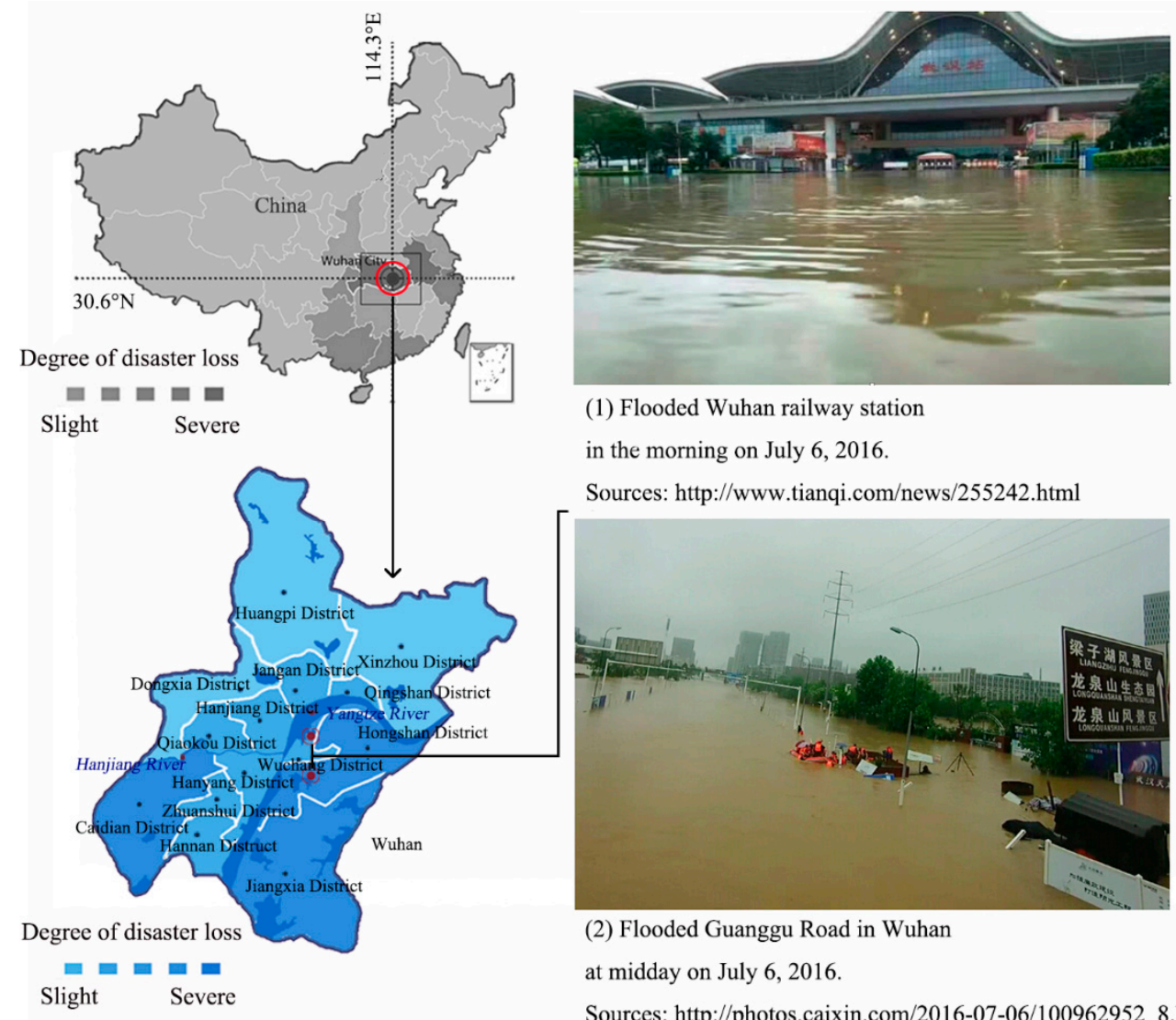

(1) Flooded Wuhan railway station in the morning on July 6,2016 .

Sources: http://www.tianqi.com/news/255242.html

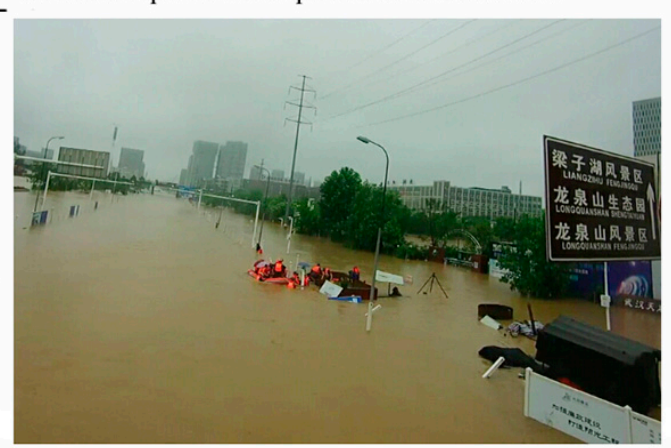

(2) Flooded Guanggu Road in Wuhan

at midday on July 6, 2016.

Sources: http://photos.caixin.com/2016-07-06/100962952_8.html

Figure 2. Study area.

From 25 June to 6 July 2016, the Wuhan meteorological station reported that the cumulative rainfall was 650.9 millimeters $(\mathrm{mm})$, and the maximum precipitation had broken all past precipitation records at this station. This was mainly due to the increase of artificial structures on both sides of rivers and lakes, which led to the encroachment and blockage of river flow. Thus, the flood storage capacity of rivers and lakes was greatly reduced. Rapidly rising water levels in lakes and rivers directly led to surface runoff that could not be discharged into the receiving water in time.

Ironically, as a piloted sponge city, Wuhan City has good drainage conditions (166 lakes and a location near the Yangtze River). Despite these conditions, the city flooded, arousing wide public concern and discussions throughout the country, especially on social media. During this event, the major news organizations and government agencies played important roles in disseminating information, providing assistance to disaster survivors, connecting with citizens, providing decision support, and disseminating common sense to individuals about where and how to receive assistance and how to participate in their own preparedness and safety. The usage of social media during the flood event improved the velocity, credibility, and richness of information related to the flood and met public demands to know more about the state of affairs regarding the flood.

\section{Data and Methods}

\subsection{Data Collection}

At present, Weibo, WeChat, and QQ are popular social media platforms in China. Sina-Weibo, launched by Sina Corp in August 2009, is the most popular social media platform in China with 462 million active users. In fact, the equivalent of Twitter in China is Sina-Weibo [32]. People can post news, opinions, comments, feelings, and anything of interest using words, photos, and videos on 
Sina-Weibo. Then, these messages are disseminated by reposts, comments, and likes according to the interests of users.

The preliminary warning of meteorological disasters by the meteorological department of the Chinese government can be released anywhere from 10 days to several hours in advance. Beginning with the first early warning and continuously updating the warning information, the public has begun to pay attention to the rainfall situation and share information on social media. According to the provisions of the National Emergency Plan for Natural Disaster Relief in China, provincial civil affairs departments are required to report to the Ministry of Civil Affairs about the disaster losses within 10 days after the disaster is stabilized. Therefore, messages posted on Sina-Weibo were collected from 10 days before to 10 days after the flood event, totaling 21 days from 25 June to 15 July 2016.

Using a Python package, we collected text messages posted or reposted by Sina-Weibo accounts using four key phrases, including "watching the sea in Wuhan", "Wuhan heavy rain", "Wuhan flood" and "Wuhan waterlogging". A total of 17047 messages were collected from Sina-Weibo. For each searched message, we extracted basic information, including the content, client type, post date, and total number of reposts, likes, and comments. "Post" and "repost" on Sina-Weibo are analogous to the terms "tweet" and "retweet" on Twitter. Then, we calculated the number of messages posted (NMP), the number of messages reposted (NMR), the total number of reposts (TNR), and the number of user accounts (NUA). Precipitation data for each day during the period was gathered from local meteorological stations.

\subsection{Methods}

We identified topics from our messages by the manner of "from word meaning to sentence meaning" [34]. Word frequency analysis was employed in all the text content of Weibo messages. Meaning recognition of words with frequency greater than 50 was carried out. According to the meaning of the word, we divided the high-frequency words into four non-overlapping word sets (opinion set, emotion set, information set, and action set). Messages that did not contain the above keywords were classified by manual identification.

Based on the semantic classification method, we classified all the messages into four categories: Information messages, action messages, emotion messages, and opinion messages. We excluded off-topic messages [34-36]. The Sina-Weibo platform uses colors to indicate different account types. Based on the color of each account, all the messages were also divided into two types: Messages posted or reposted by organization accounts, and other messages posted or reposted by individual accounts.

Pearson correlations were calculated between amount of precipitation and NMP, NMR, NUA, and TNR on the same day until the fourth day. We compared these correlation coefficients and their significance in each classified message and identified whether there was a significant time lag between the precipitation and public response to flood events. Based on the reposting relationships of messages, we constructed networks between Sina-Weibo accounts, which were visualized by the Gephi software. In the networks, it is easy to determine the position of each account and its importance.

\section{Results}

\subsection{General Overview}

During the flood event, there were two precipitation peaks (Figure 3). The first one occurred on 1 July and lasted until 2 July, with a cumulative precipitation of $315.9 \mathrm{~mm}$. The second occurred on 6 July, with an accumulated precipitation of $241.5 \mathrm{~mm}$. NMP also had two peaks: The first peak appeared on 1 and 2 July and then began to fall over the next few days until 5 July. The second peak appeared on 6 July and then declined. Of all the messages, only 2480 messages (approximately $17 \%$ of the total number) were reposted (a total of 56258 times). Most reposting occurred during 2-3 and 6-9 July and was accompanied by heavy rain. 


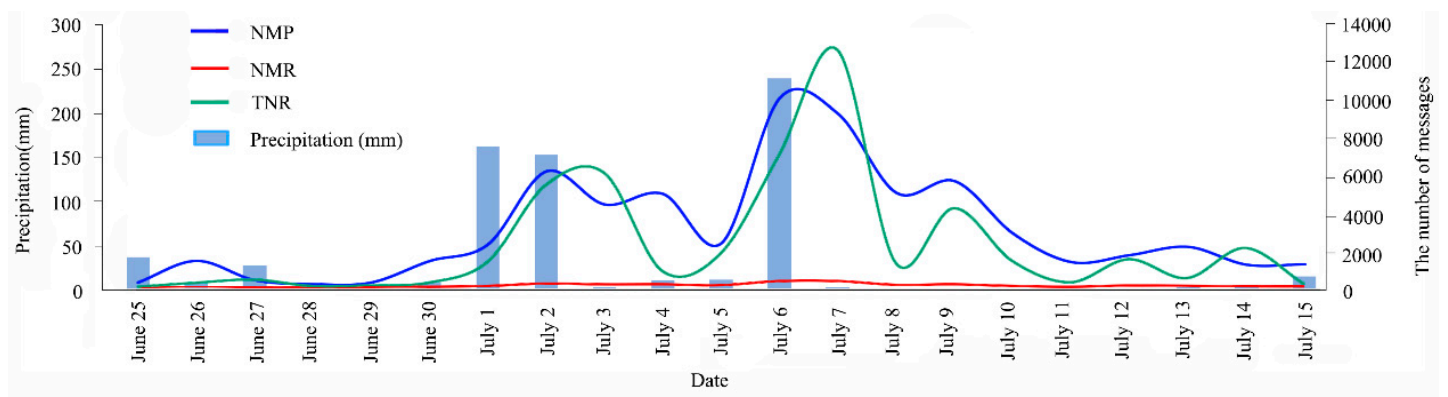

Figure 3. Messages and precipitation during the flood event.

\subsection{Classification of Messages}

Based on content, all the messages were divided into four types and off-topic messages (Table 1). Although off-topic messages were reposted frequently, the messages were excluded from this study because off-topic messages were not directly related to the flood event. The information messages were the most common, followed by action, opinion, and emotion messages. Of the four types of messages, action messages were reposted the most, and emotion messages were reposted the least, which implies that the public is more willing to discuss and engage in practical action than express emotion during a flood event. Each action and opinion message was commented on an average of over eight times. In these messages, users discussed urban planning problems, rescue issues, donation issues, and ways to avoid or reduce losses in the next disaster. Accordingly, these two types of messages also had more likes than the other two types of messages. Each information or emotion message was only commented on over three times on average. In fact, these two types of messages only play the role of informing and do not promote public thinking and discussion. Therefore, these messages received fewer likes than the others.

Table 1. Numbers of each type of message that are reposted, commented on, and liked.

\begin{tabular}{|c|c|c|c|c|c|}
\hline & $\begin{array}{c}\text { Information } \\
\text { Messages }\end{array}$ & $\begin{array}{c}\text { Action } \\
\text { Messages }\end{array}$ & $\begin{array}{c}\text { Opinion } \\
\text { Messages }\end{array}$ & $\begin{array}{c}\text { Emotion } \\
\text { Messages }\end{array}$ & $\begin{array}{l}\text { Off-Topic } \\
\text { Messages }\end{array}$ \\
\hline $\begin{array}{c}\text { Number } \\
\text { (Proportion to Total } \\
\text { Number) }\end{array}$ & $\begin{array}{l}11933 \\
(70 \%)\end{array}$ & $\begin{array}{l}1875 \\
(11 \%)\end{array}$ & $\begin{array}{l}1534 \\
(9 \%)\end{array}$ & $\begin{array}{l}1364 \\
(8 \%)\end{array}$ & $\begin{array}{c}341 \\
(2 \%)\end{array}$ \\
\hline $\begin{array}{l}\text { Average Number } \\
\text { of Reposts }\end{array}$ & 3.82 & 8.19 & 5.95 & 1.54 & 21.25 \\
\hline $\begin{array}{l}\text { Average Number } \\
\text { of Comments }\end{array}$ & 3.40 & 8.28 & 8.10 & 3.10 & 23.68 \\
\hline $\begin{array}{l}\text { Average Number } \\
\text { of Likes }\end{array}$ & 9.33 & 34.91 & 17.92 & 10.44 & 27.23 \\
\hline
\end{tabular}

\subsection{Messages Posted by Organization and Individual Accounts}

Sina-Weibo accounts are marked by the symbol V with colors. The accounts marked with a blue $\mathrm{V}$ belong to government, corporate, institution or news organizations and are called organization accounts. In this study, organization accounts include social organization accounts, government agency accounts, and news organization accounts. The accounts marked with a yellow $\mathrm{V}$ indicate that users are members of the general public, and the accounts marked with a golden or red $\mathrm{V}$ indicate that the users are celebrities, such as singers, actors, or other people with reputation and influence, and are called individual accounts in this study. There are far fewer organization accounts than individual accounts. In detail, there are only 985 organization accounts and 12,778 individual accounts. Correspondingly, there were only 2194 messages (approximately 13.13\% of the total messages) posted by organization accounts, and 14,512 messages (approximately $86.87 \%$ of the total messages) posted by individual accounts. However, messages posted by organization accounts were more frequently reposted, commented on, and liked than those posted by individual accounts. Each message posted 
by an organization was reposted, commented on, and liked, on average, up to 16.4 times, which is over 10 times more than that of messages posted by individual accounts. Similarly, in the study of the 2012 tsunami in Indonesia, it was also found that the single message of the organization accounts was reposted much more than the individual accounts [37]. This is because the information source of organization accounts is wide, these accounts can post disaster warnings and accurate disaster messages quickly, and their messages can be spread more extensively. In other words, messages posted by organization accounts are widely dispersed and of interest to the public, although the absolute number of messages is not large. A small number of accounts post many messages, and most accounts post very few messages (Figure 4). For example, 419 messages were posted by the Ridge Channel, Hubei Provincial Government Portal, Hubei Daily News, Hubei Publish and National Emergency Broadcast, accounting for $2.5 \%$ of the total messages. Although they only account for $0.04 \%$ of the total number of accounts, one single account published 83.8 messages on average. The average published number of these accounts far exceeds that of individual accounts. We call these accounts kernel accounts.

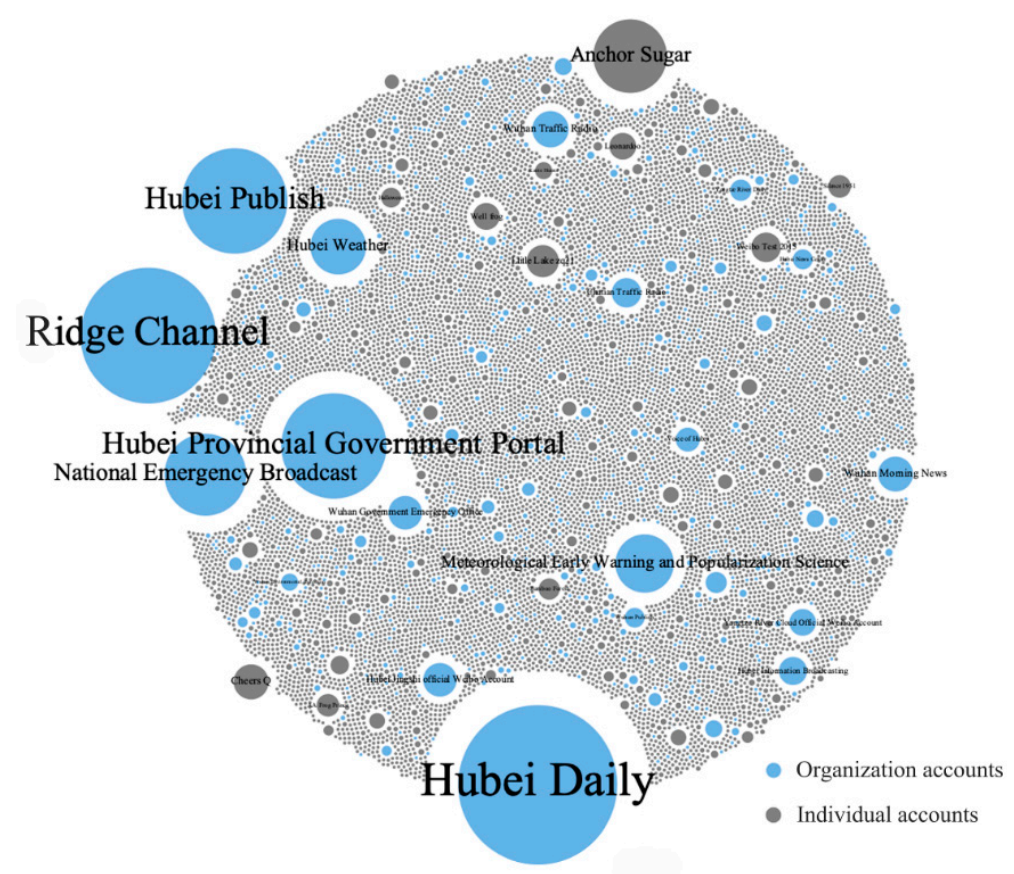

Figure 4. Accounts posting messages during the flood event. The size of the account reflects the number of messages posted by the account.

When an emergency occurs, the public usually falls into panic and speculation due to insufficient and inaccurate information [38]. Messages including authoritative information posted in a timely manner by government agencies are conducive to eliminating accidents, managing misinformation, stabilizing public sentiment, and preventing the outbreak of a second crisis. For example, the Ridge Channel, Hubei Publish, Hubei Daily News, and Hubei Provincial Government Portal can release and update meteorological information in a timely manner with the permission of the government. This kind of information is exactly what the public wants to know about the changes in rainfall and it provides great situational awareness and informed decision-making. In addition, as a key element in the mass communication field, news organizations play an important role in the dissemination of information about public events on the internet. News organizations also provide early warnings regarding public emergencies, coordinate social relations, lead public opinion, monitor and reflector on events, and are responsible for the function of social safety valves. Therefore, nine of the ten accounts that posted the most messages are organization accounts. The messages posted by organization accounts generally exceed 80 words, and most of them are information or action messages, including 
weather forecasts and disaster information. Additionally, most messages posted by individual accounts tend to be fragmented emotion or opinion messages with fewer than 80 words.

\subsection{Pearson Correlation between Messages and Precipitation Amount}

Initially, there are few messages related to the flood event on social media, but the public is eager to know information about rainfall or flooding, so these messages are reposted explosively. Thus, the correlation between TNR and precipitation has the strongest correlation on the same day (Table 2). As time goes by, the public can get much information related to rainfall or flooding through other media (television, radio, newspapers, websites, etc.). Users become increasingly active on social media and pay attention to the flood situation, exchange information, and express their feelings and emotions [38]. Sina-Weibo generates massive amounts of news every moment, and in addition to trending events based on clicks, it will recommend messages according to user preferences. On the one hand, this mode can be tailored to more interesting content for users and can also save time to a certain extent, but it may cause a slow dissemination rate for important information that has not yet received attention. On the other hand, unlike other unexpected hot social topics, only sustained heavy rainfall can cause floods. Therefore, there is a certain time-lag effect between the occurrence of flooding and general public attention. The correlations between precipitation and NMP, NMR, and NUA on the next day are more significant than those on the same day or other days (Table 2).

Table 2. Pearson correlation coefficients between precipitation and messages.

\begin{tabular}{|c|c|c|c|c|}
\hline & $\begin{array}{l}\text { The Same Day } \\
\qquad N=21\end{array}$ & $\begin{array}{c}\text { One-Day Lag } \\
N=20\end{array}$ & $\begin{array}{c}\text { Two-Day Lag } \\
\text { N = } 19\end{array}$ & $\begin{array}{c}\text { Three-Day Lag } \\
\mathrm{N}=18\end{array}$ \\
\hline NMP & $0.482^{* *}(\mathrm{P}=0.027)$ & $0.542^{* *}(\mathrm{P}=0.014)$ & $0.200(P=0.413)$ & $0.130(P=0.606)$ \\
\hline TNR & $0.487^{* *}(\mathrm{P}=0.025)$ & $0.411 *(\mathrm{P}=0.072)$ & $0.089(\mathrm{P}=0.717)$ & $0.201(\mathrm{P}=0.423)$ \\
\hline NMR & $0.502 * *(\mathrm{P}=0.020)$ & $0.545^{* *}(\mathrm{P}=0.013)$ & $0.122(\mathrm{P}=0.617)$ & $0.084(\mathrm{P}=0.739)$ \\
\hline NUA & $0.485^{* *}(\mathrm{P}=0.026)$ & $0.540 * *(\mathrm{P}=0.014)$ & $0.195(\mathrm{P}=0.423)$ & $0.126(\mathrm{P}=0.617)$ \\
\hline
\end{tabular}

Based on the same correlation analysis, there are time lags between precipitation and messages for each type of message, as shown in Table 3, and most of these are one-day lags. In detail, there is no time lag between precipitation and TNR in information messages. The possible reason is that there was not enough information at the beginning of the flood, so local users quickly reposted what they see or hear from the real world or the internet. There is a three-day lag between precipitation and the TNR of opinion messages, which means the interactivity of opinion messages can last for three days or more. When people are exposed to floods, the public's psychology and emotions are affected. By transmitting information on the internet through social media, people can reduce anxiety, express sympathy and dissatisfaction, and gain situational awareness [33]. For emotion messages, therefore, the correlations between precipitation and NMP and NUA are highest on the same day (no time lag).

Table 3. Time lags for the four types of messages.

\begin{tabular}{ccccc}
\hline & Information Messages & Action Messages & Opinion Messages & Emotion Messages \\
\hline NMP & 1 & 1 & 1 & 0 \\
TNR & 0 & 1 & 3 & 1 \\
NMR & 1 & 1 & 1 & $/$ \\
NUA & 1 & 1 & 1 & 0 \\
\hline
\end{tabular}

0: No time lag, 1: One-day lag, 2: Two-day lag, 3: Three-day lag/No significant correlation.

Pearson correlation coefficients were also calculated between precipitation and messages posted by organization and individual accounts. In general, the most correlations are between precipitation and NMP, NMR, NUA of both organization and individual messages on the next day (one-day 
lag). Only the correlation relationship between precipitation and the TNR of messages posted by organization accounts has a three-day lag effect. The possible reason is that heavy rainfall gradually moved downstream along the Yangtze River, where the public may have searched for related warning messages and reposted these messages. In addition, it can be speculated that people are more inclined to exchange opinions under the messages posted by the organization accounts. The TNR of individual accounts on the next day has a significant correlation with precipitation, that is, the one-day lag effect.

In fact, the time lag effects include three parts: (1) A time lag from the beginning of rainfall to public perception of rainfall, then to response on social media; (2) a time lag from floods to public perception, then to response on social media; and (3) a time lag from the beginning of rainfall to floods, then to public perception, then to response on social media (Figure 5). Factors such as the type of disaster, geographical differences, network penetration, etc., should affect the length of the lag time, but in general, the shorter the lag is, the more beneficial it is to reduce economic losses and casualties.

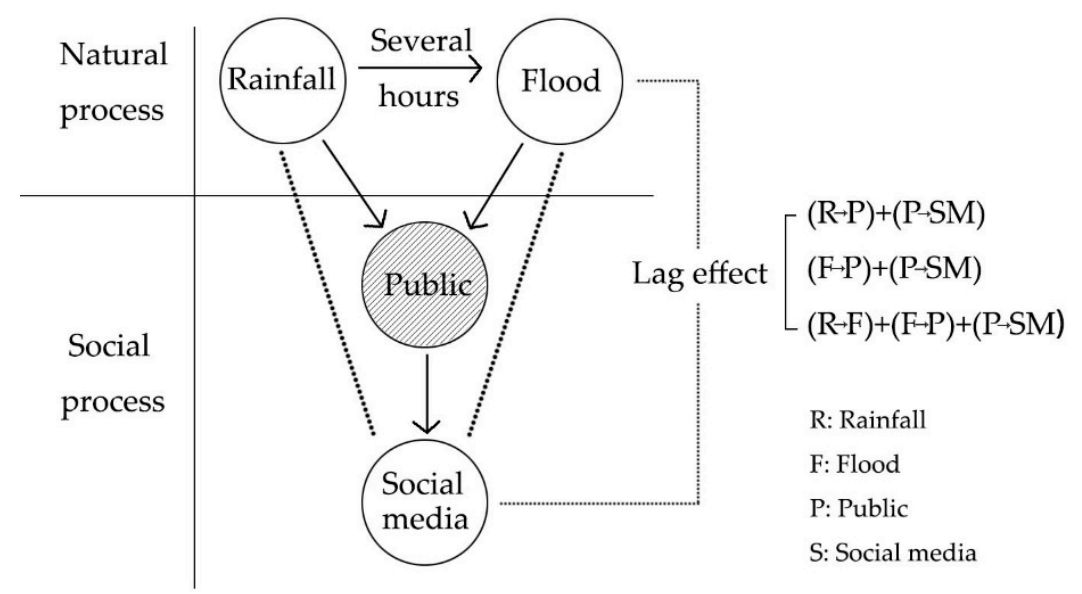

Figure 5. The types of lag effect.

\subsection{Dissemination Speed}

Information dissemination is mainly carried out by reposting on social media. The speed of information dissemination is reflected by when and how many messages are reposted, which can also reflect the response and attention of government agencies, news organizations and individuals. Floods occur after a precipitation accumulation process. Correspondingly, the time of posting message is different, and there is no fixed starting time for all messages. For each message, we extracted the time it was posted and the time it was reposted each time. Then, we identified the trend of the number of messages reposted over time (Figure 6). Messages were quickly disseminated by reposting within $14 \mathrm{~h}$ after being posted, especially within $2 \mathrm{~h}$ after being posted, and began to decline after $4 \mathrm{~h}$. Messages were rarely reposted $48 \mathrm{~h}$ after the messages are posted, which is not shown in Figure 6. In general, there is a significant power function relationship between the TNR and time.

At the beginning of the flood, messages related to flooding are not enough. In particular, there is a lack of government agency messages, which makes the public pay attention to only the latest information. Therefore, the outdated messages about flood events are quickly overwhelmed. In short, if messages are not being reposted in the first four hours, the possibility of being reposted again over time decreases. Although the popularity of flood information can only be maintained for a short time, the dissemination of these messages occurs over a longer period. This phenomenon is called the "long tail effect" [39]. Even when the rainfall passed, the public's attention did not come to an end. As long events could make the public think of the flood, relevant messages were searched again and reposted. The four types of messages also have a "long tail effect" similar to the overall trend, with the trend of messages decaying quickly within four hours and then maintaining a very slow downward trend accompanied by fluctuations. Action and opinion messages received more attention in the first few hours than information and emotion messages, and opinion messages were disseminated faster 
than other messages. The heat attenuation of information messages was the slowest of all the types of messages.

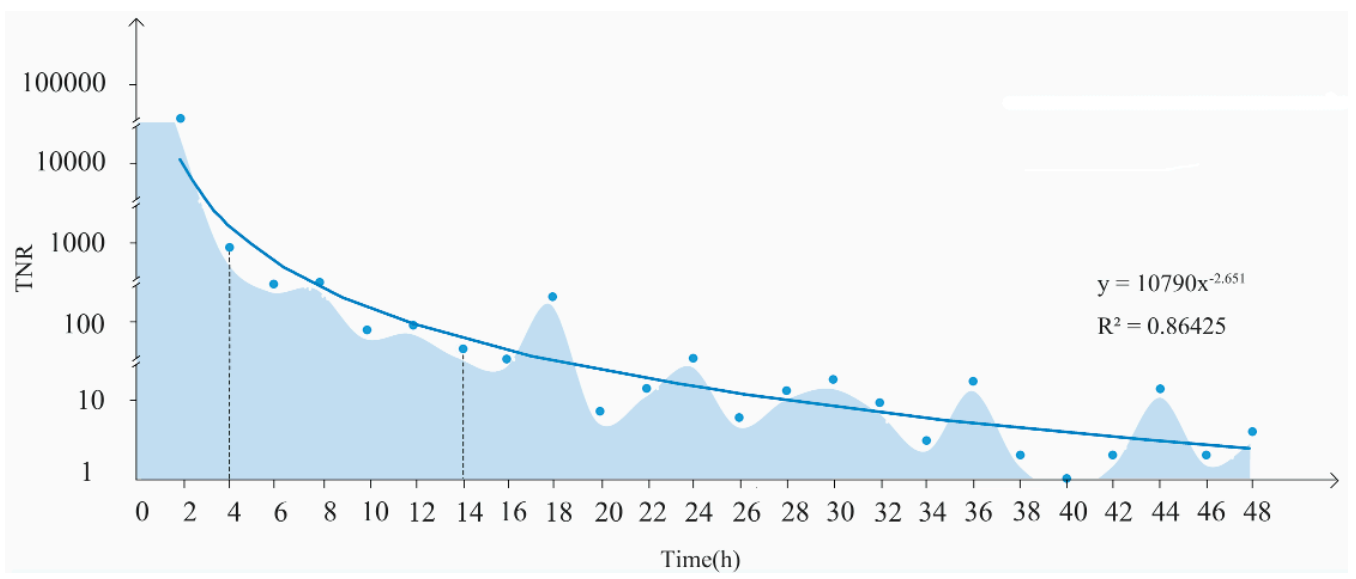

Figure 6. The trend of the number of repostings over time after posting.

In addition, there are also obvious differences in the reposting of messages posted by organization and individual accounts, although both have significant a "long tail effect" (Figure 7). Organization messages were reposted more than individual messages within $20 \mathrm{~h}$, and the opposite was true after $20 \mathrm{~h}$.

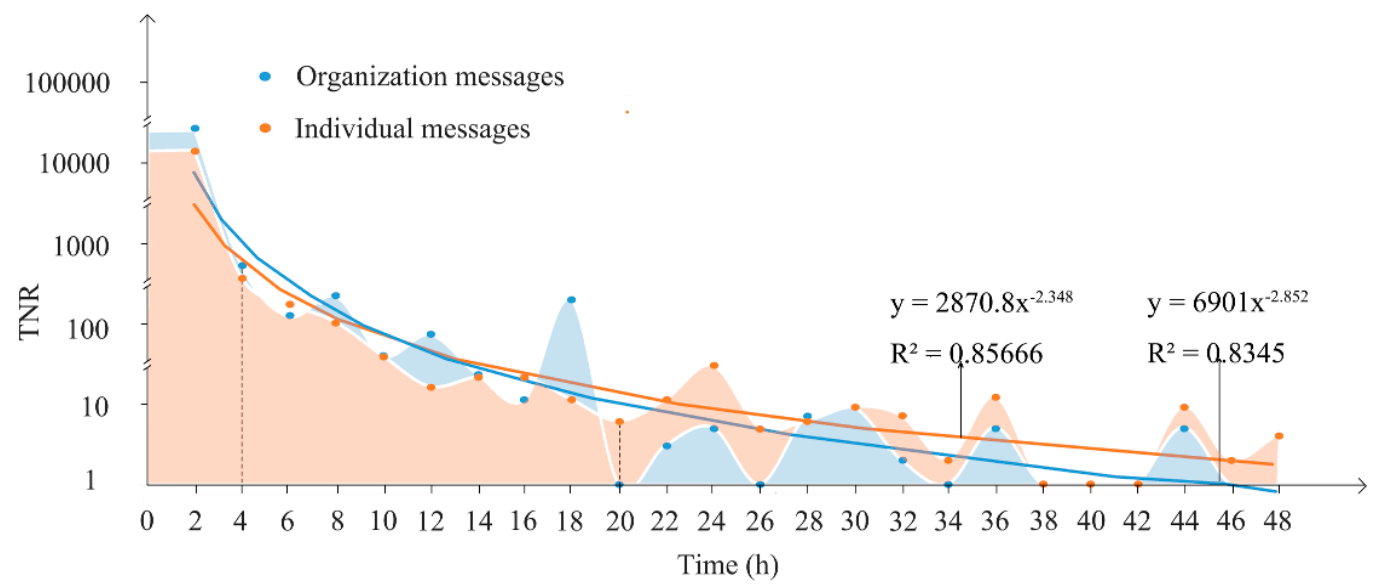

Figure 7. The trend in the number of repostings over time after posting organization messages and individual messages.

There are weak relationships between organizations and their followers since there are weak relationships based on network information, users are unknown to each other, and users are able to follow and cancel anytime [40]. Messages posted by organizations are formal and easily read by followers, which increases the possibility of messages being reposted due to the existence of many followers [41]. With increasing amounts of information appearing on social media, the public begins to identify useful or reliable information, express their understanding and views, breaks the previous one-way information sharing model with organizations, and expects effective two-way communication. As time goes on, it is easier for individual messages based on strong relationships to obtain trust and support, and these receive more attention and discussion by the model of two-way communication, so reposting may be higher for these than for organization messages. Communications between individual accounts and their followers through comments and reposting can deepen the understanding of the information and can completely express opinions. Therefore, some messages 
posted by individual accounts can maintain the heat attenuation for a longer time than messages posted by organization accounts.

\subsection{Reposting Relations in Social Networks}

According to the relationships of messages being reposted by accounts, a network graph was visualized using Gephi software, as shown in Figure 8. Each node in the graph represents a Sina-Weibo account, and its size is based on the number of reposts that account received. The blue nodes represent general public users, red nodes represent social organization users, green nodes represent celebrity users, purple nodes represent government agency users, and pink nodes represent news organization users. Each edge (the line connecting a pair of nodes) represents a repost between two accounts, and thicker lines mean more repostings.

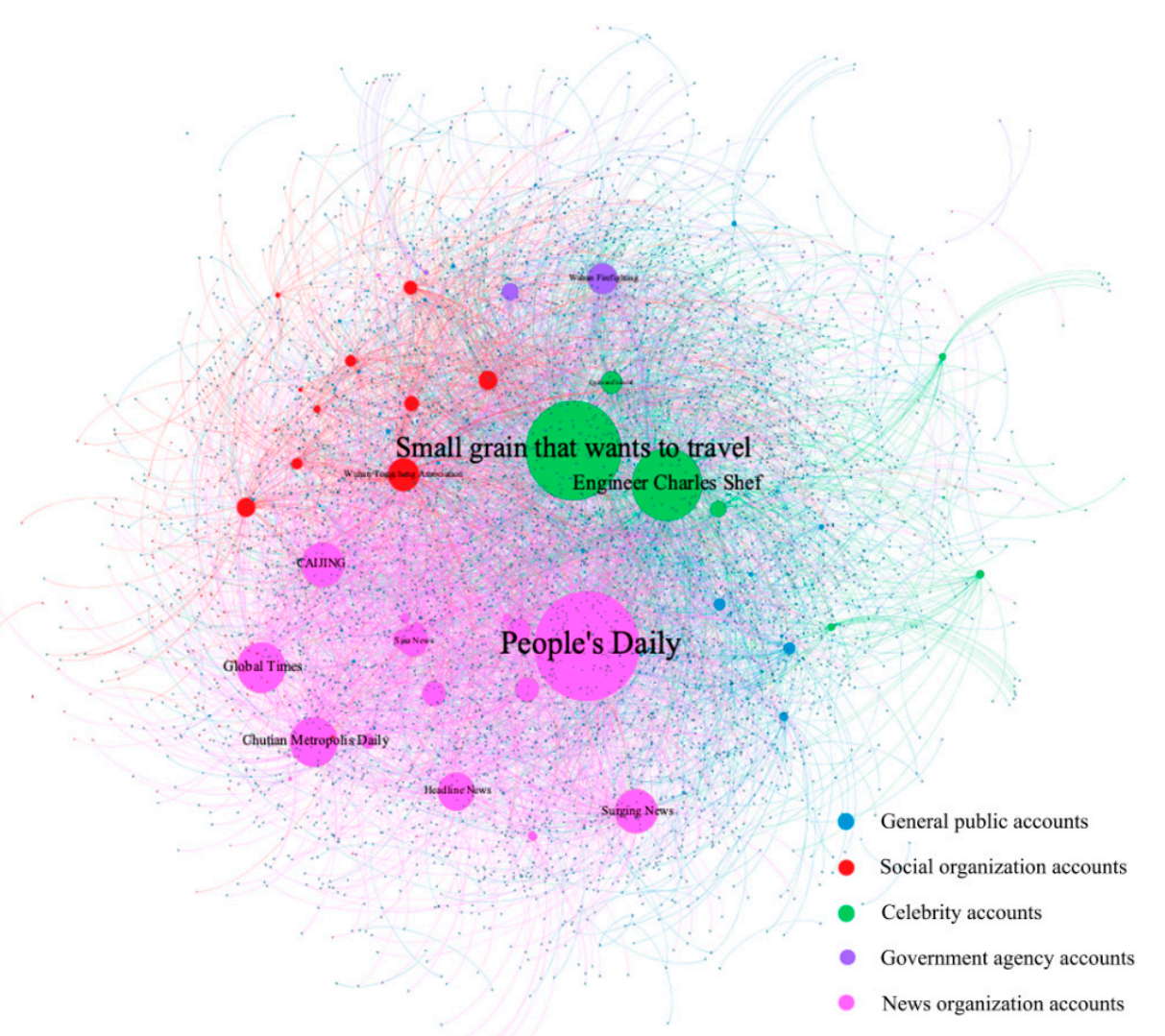

Figure 8. Network diagram of messages being reposted among accounts.

Of all the accounts, messages posted by China Daily are reposted most frequently, up to 4517 times, followed by CAIJING, Small grain that wants to travel, Engineer Charles Shef, and the Global Times, whose messages are reposted more than 2000 times. In addition, there are five accounts (Chutian Metropolis Daily, Surging News, Headline News, Sina News and Wuhan Tongcheng Association) whose messages are reposted more than 1000 times. Table 4 shows the numbers of messages posted by these accounts and the number of these messages that are reposted by other accounts. Surprisingly, these accounts only post several messages, but their messages are frequently reposted. 
Table 4. Top 10 accounts.

\begin{tabular}{cccccc}
\hline Order & Account Name & Account Type & NMP & TNR & Fans (Million) \\
\hline 1 & People's Daily & News organization & 5 & 4517 & 68.6 \\
2 & CAIJING & News organization & 3 & 4183 & 28.73 \\
3 & Small grain that wants to travel & Individual (celebrity) & 1 & 3991 & 0.79 \\
4 & Engineer Charles Shef & Individual (celebrity) & 1 & 3040 & 0.07 \\
5 & Global Times & News organization & 4 & 2014 & 14.07 \\
6 & Chutian Metropolis Daily & News organization & 2 & 1882 & 11.12 \\
7 & Surging News & News organization & 1 & 1796 & 11.1 \\
8 & Headline News & News organization & 4 & 1602 & 54.82 \\
9 & Sina News & News organization & 3 & 1241 & 13.58 \\
10 & Wuhan Tongcheng Association & Social organization & 5 & 1105 & 0.95 \\
\hline
\end{tabular}

Except for two individual accounts and one social organization account, the other seven accounts belong to news organizations whose messages are heavily reposted because they have many followers. Messages posted by news organizations are characterized by timeliness and are easily reposted by the public, which has attracted widespread attention. Although the followers of the two individual accounts are fewer than the followers of the news organizations, they far exceed the followers of other individual accounts. Small grain that wants to travel is a well-known fashion blogger with more than 190,000 fans, and all of his/her messages are viewed more than one million times by followers every day. Engineer Charles Shef is a commentator with 70,000 followers. The two accounts belong to well-known accounts on social media that have celebrity effects. Due to the audience's respect for celebrities, they tend to adopt celebrities' suggestions and opinions and have a strong willingness to repost their messages and find a sense of "collective identity". A celebrity's single message during the flood period was reposted more than 3000 times, which may have affected the public's perception of whole events. This finding is consistent with Tang's (2013) assertion that in communities where leaders are aware of an emergency, more prevention or relief actions are taken than where awareness is lacking [42]. The messages posted by the Wuhan Tongcheng Association (a social organization composed of citizens with the same interests and hobbies) have also been widely reposted on social media because it has many followers and a good reputation among local citizens. Therefore, the public's awareness and response to disasters is increasing on social media.

It is worth mentioning that there are no government agency accounts among the top 10 accounts, meaning that government agencies do not play a leading role in the information dissemination process on social media. We can call these accounts leading accounts. However, leading accounts are completely different from kernel accounts (Figure 4). Although kernel accounts posted many messages, these messages were not widely dispersed by reposting. This fact implies that government agencies did not use the Sina-Weibo platform as an important way to post information related to the flood event and to respond to the public's responses.

\section{Discussion}

\subsection{Responses to Disasters on Social Media in Western Countries and China}

Like in Western countries, social media played an important role in urban flood disaster event in China, especially in information sharing and situational awareness in in the stage of disaster response. For example, the majority of messages posted during disasters are about the traffic, weather situation, and disaster relief $[28,33,43]$. If related messages are not being reposted in the first few hours, the possibility of being reposted again over time decreases, but it will not stop for a long time (long tail effect). Mersham (2010) explained this phenomenon as that the conversations of netizens can create a long-lasting impact because they can be re-referenced and accessed quite simply in similar disaster event [44]. In general, the dissemination of all the disaster-related messages show a long tail effect in both Western countries and China. 
In China, however, $56.7 \%$ of the total population are netizens, which just reaches the average global level (56.8\%) but is far below that of the United States (95.6\%). Furthermore, most active users on social media are young people under the age of 30 . Middle-aged and older people are limited by technology, the economy, and education level, and they cannot obtain disaster warnings from social media.

In addition, there are obvious differences in cultural backgrounds between Western countries and China. Western values believe that the lifestyle and quality of life of each individual depend on their ability [45]. The Chinese emphasize group and social consciousness [46,47]. So, Chinese people are more likely to follow the herd subconsciously and face difficulty questioning existing opinions. Therefore, the messages posted on the social media with a function of public opinion guidance are easier to be disseminated in China. It also noticed that seven of the ten accounts with messages most frequently reposted in the floods were news organization accounts. Western culture encourages individual innovation. Chinese people pay attention to modesty and prudence. Westerners value individual freedom and are unwilling to be restricted. Chinese culture emphasizes collectivism, advocates that individual interests should be subordinate to collective interests, and expresses little about individual needs. In the Western countries, individual personality, freedom, and equality are more important. Therefore, in the BP Deepwater Horizon oil spill event, the third most frequently reposted account was the ordinary individual account [6]. In the Wuhan event, none of the 10 most frequently forwarded accounts were an ordinary individual account.

In most Western studies, people pay more attention to information messages [32,48]. However, action messages attract public attention and were reposted most during the Wuhan flood and other disasters in China [35]. Because $43.3 \%$ of the total population are not netizens in China, their access to information related to disaster is relatively single, mainly relying on traditional media such as television and newspapers, especially for older people. The public cannot obtain enough information in time, which makes it impossible for them to judge the development of disasters and take appropriate action. So, they rely more on action information to tell them what to do than their own judgments. This is also reflected on the social media where the public is more inclined to repost and comment on action messages. Of course, this also implies that the popularization of disaster awareness education in China is not enough and needs to be improved.

Individuals are the highest contributors of messages on social media networks during disasters $[36,43,49]$. During the Wuhan flood event, the messages posted by news organization accounts were most widely disseminated, but messages posted by government agencies and non-governmental organizations (NGOs) were not widely disseminated. The opinions of the general public were drowned out and were not taken seriously in the vast number of messages. On the contrary, in Western countries, government agencies and influential individuals including reporters, celebrities, and critics play leading roles $[14,36,50]$.

Based on reposts and likes, we found that two-way communication was relatively rare on social media during the Wuhan flood event, except for few messaged posted by several celebrity accounts. Meanwhile, the information from authority departments (government agencies and NGOs), which was urgently needed by the public, rarely involved in two-way interaction. Since 2013, Wuhan city has invested more than 13 billion Chinese Yuan in the treatment of urban drainage systems. In addition, Wuhan city was officially selected as the first national "sponge city" construction pilot in April 2015. However, when the public questioned the effectiveness of these investments on the social media, they did not receive any effective response during the flood event. Frequent two-way communications between posters and commentator can not only attract more people to join the discussion, but also allow posters and commentators to share more information with each other, revealing the truth of the disaster event in time. On the contrary, two-way communication is very active on social media in Western countries.

In addition, we further searched for messages from Sina-Weibo after the floods event (from 16 July to 15 September). The results show that the public discussion of flood disasters was very little during 
the mitigation and recovery stages, which indicates that the public's interest in disaster mitigation and recovery is far less than that of disaster events themselves. It seems that the public soon forgot about the flood event. On 21 June 2019, Wuhan suffered heavy rains again. As a result, the phrase "watching the sea in the city" once again became a hot topic on social media, which responses to an old Chinese saying, "once on shore, one prays no more". That is, in the stages of mitigation and recovery, the role of social media in China was still far less than that of Western social media.

\subsection{Differences in Responses to Various Natural Disasters}

Social media holds great hope for leveraging public participation in disaster responses [4]. It is difficult to identify the precise beginning of flood disasters, and they have a long-term impact on the productivity and lives of residents [51]. Flood disasters provide enough warning time, and the entire disaster process can be divided into different stages. Responders can implement different measures at different stages, and researchers can study the responses of people to different stages in detail. During flood disasters, government emergency agencies have the responsibility to verify information before posting it. The number of messages posted by the government lag behind those of news organization but have much higher accuracy. The public's main concern is information acquisition during such disasters. In terms of disasters such as earthquakes, disaster situations are often more difficult to predict, so instead of providing status updates, rescue needs are the most important. Disasters such as droughts are different from the two above types. Droughts do not attract public attention within a certain period, and usually only a few specific groups are conscious of the disaster [52,53]. As a result, there are rarely relevant messages on social media. Therefore, we believe it is necessary to conduct further research on the responses to different disaster types with different duration periods and different regional or cultural environments to study how to responses are correspondingly affected and to further refine the response step.

\subsection{Emergency Management Models}

Social media is clearly changing the ways in which people communicate during disaster events. Emergency responders are beginning to understand that they cannot ignore these new channels. For example, the U.S. Department of Homeland Security's Science and Technology Directorate (DHS S\&T) established a virtual social media working group (VSMWG). The mission of the VSMWG is to provide guidance and best practices to the emergency preparedness and response community on the safe and sustainable use of social media before, during, and after emergencies. However, Chinese emergency response framework system was initially formed on 8 January 2006. In addition, the Emergency Management Department of China was established on 13 March 2018. Therefore, China has not yet formed a special disaster emergency guidance system based on social media, and social media has not been used as a systematic tool throughout all links of risk communication. In the Wuhan flood event, the messages posted by emergency departments were mainly derived from the National Emergency Broadcasting and Wuhan Municipal Government Emergency Office. These agencies posted 83 messages, of which 78 were early-warning messages, one was a self-rescue message, and the rest were real-time torrential rain damage and casualty messages with an average 565 reposts. Although messages from government agencies focused mostly on early warning and were more comprehensive than those of news organizations, the messages posted by government agencies were reposted less often than those of news organizations. During the 2010 BP Deepwater Horizon Oil Spill incident, only one of the top ten reposted accounts was that of a news organization, one was that of a government agency, and the most (five accounts) were those of influential individuals, including reporters, celebrities, and critics [14]. During the Wuhan flood event, however, most of the reposted messages were those from news organization accounts and two celebrity accounts. None of the reposted messages were from government agency accounts. Therefore, social media has not played the eight roles mentioned by the Virtual Social Media Working Group and Department of Homeland Security First Responders Group. Some opinion leaders, especially celebrities with accounts marked with a large V in the 
Sina-Weibo platform, should assist government agencies in improving information dissemination and communication with the public. After the disaster, we can timely obtain information on how to save ourselves and how to obtain relief or materials in time.

\subsection{Factors That Influence the Use of Social Media in Disasters}

With the development of mobile client, more and more young people have began to initiate contact through social media. According to the annual report of Sina-Weibo in 2018, users aged 23-30 accounted for the highest proportion, reaching $40 \%$, followed by $18-22$ years old (35\%), 31-40 years old $(14 \%)$, and the lowest was those aged over 41 years old, accounting for only $5 \%$. Therefore, age is an important factor influencing the use of social media in disasters [54].

In addition, having enough active time in social media means having enough time and convenient access to the Internet. In a fixed workplace, netizens engaged in mental work can pick up mobile phones to pay attention to disaster information and repost interesting content at any time. For netizens engaged in special jobs, such as mechanical workers, workshop workers and so on, only after work or during weekends can they have enough time to surf the internet to pay attention to the development of disasters. Similarly, for high-income and highly educated people, more attention is paid to environmental problems or individual psychological aspects. Therefore, the background of education and income may also lead to different public attention to the disaster information.

Secondly, $56.7 \%$ of the total population is netizens in China, which only reaches the global average $(56.8 \%)$ but is far below that of the United States (95.6\%). Part of the problem is that older people are unable to access disaster information through the internet because they do not use smartphones. The other part is that the residents in remote mountainous areas are affected by poor economic conditions, low educational level, or the absence of network in the whole area. They still get information through traditional media such as radio, newspaper and television.

Finally, Chinese early warning information is mainly issued and updated by competent meteorological departments at all levels. No organization or individual can issue an early warning in any form. Once found, the early warning will be criticized by warning, and the organization or individual may even face a fine. Therefore, Chinese people mainly accept information passively. There is also a lack of two-way communication between government departments and the public, and thus, different ways of emergency and network management may lead to different public response speed.

\section{Conclusions}

In the stages of preparedness and response, social media plays an important role in urban flood disaster events in China, especially in information sharing including weather forecast, traffic situation, and what witnesses see and hear. We found that there is a significant time-lag effect (one day) between precipitation peaks and general public participation, and there is a three-day lag between the precipitation peak and the dissemination of opinion messages. All messages are quickly disseminated within two hours after they are posted and then maintain a stable slow dissemination speed. Although the heat of messages lasts for only a short time, dissemination does not stop for a long time. Organization messages are more likely to be reposted than individual messages within $20 \mathrm{~h}$, but the heat attenuation of organization messages is faster than that of individual messages. The content of messages posted by government agencies is more comprehensive and has more information about early warnings than those of news organizations. People tend to exchange opinions when they repost organization messages, and the popularity of such communications lasts for three days or even longer. Individual messages posted by celebrities are easily disseminated on social media. The public does not have enough sense of disasters and subconsciously thinks that natural disasters are far away from them. Moreover, the government does not make good use of social media, especially the function of two-way communication, and most of the emergency department followers are not active. Therefore, useful warning information was not disseminated quickly through social media. Compared with social media in Western countries, the public cannot obtain enough information from Chinese social media 
in time. Social media has not played other important functions, such as two-way communication, decision support, and so on.

Our findings can be applied to other natural disasters to ensure that the credible messages posted by organization accounts can be disseminated more quickly and widely after a disaster. For example, adding opinions content to the message posted by the organization accounts may promote the persistence of information dissemination. The time-lag effect between public response and precipitation may provide insights into the study of disasters with time-lag effects such as debris flows and landslides. The implementation of timely self-rescue can effectively reduce the threat of life and property losses caused by disasters.

In future work, more factors should be considered, such as users' gender, age, occupation, and location (cities, villages). It is necessary to improve the method of using and explore the public's response to emojis, pictures, and videos from social media during disasters. The public participant in the all stages of disasters (preparation, response, mitigation, and recovery) is also worth studying further.

Author Contributions: Data curation, X.C. and Y.Z.; Formal analysis, X.C. and L.L.; Funding acquisition, G.H.; Investigation, X.C.; Methodology, X.C.; Project administration, G.H.; Resources, G.H.; Software, X.C.; Supervision, G.H.; Validation, X.C. and L.L.; Visualization, G.H. and X.C.; Writing—original draft, X.C.; Writing—review \& editing, G.H.

Funding: This research was funded by the National Natural Science Foundation of China (Grant No. 51778077, 51978091).

Acknowledgments: We thank anonymous peer reviewers for their helpful feedback to improve this work.

Conflicts of Interest: The authors declare no conflict of interest.

\section{References}

1. Boyd, D.; Ellison, N. Social network sites: Definition, history and scholarship. J. Comput. Mediat. Commun. 2010, 13, 210-230. [CrossRef]

2. Guan, X.; Chen, C. Using social media data to understand and assess disasters. J. Nat. Dis. 2014, 74, 837-850. [CrossRef]

3. Cosenza, V. World Economic Forum. Available online: https://www.weforum.org (accessed on 1 July 2018).

4. Yates, D.; Paquette, S. Emergency knowledge management and social media technologies: A case study of the 2010 Haitian earthquake. Proc. Am. Soc. Inf. Sci. Technol. 2011, 31, 6-13. [CrossRef]

5. Bunce, S.; Partridge, H.; Davis, K. Exploring information experience using social media during the 2011 Queensland floods: A pilot study. Aust. Libr. J. 2012, 61, 34-45. [CrossRef]

6. Starbird, K.; Dailey, D.; Walker, A.H.; Leschine, T.M.; Pavia, R.; Bostrom, A. Social media, public participation, and the 2010 BP deepwater horizon oil spill. Hum. Ecol. Risk Assess. 2015, 21, 605-630. [CrossRef]

7. Xiao, Y.; Huang, Q.; Wu, K. Understanding social media data for disaster management. J. Nat. Dis. 2015, 79, 1663-1679. [CrossRef]

8. Ngamassi, L.; Ramakrishnan, T.; Rahman, S. Use of social media for disaster management: A prescriptive framework. Organ. End User Comput. 2016, 28, 122-140. [CrossRef]

9. Jurgens, M.; Helsloot, I. The effect of social media on the dynamics of (self) resilience during disasters: A literature review. J. Cont. Crisis Manag. 2018, 26, 79-88. [CrossRef]

10. VSMWG \& DHSFRG. Lessons Learned: Social Media and Hurricane Sandy; U.S. Department of Homeland Security: Washington, DC, USA, 2013.

11. Tang, Z.; Zhang, L.; Xu, F.; Vo, H. Examining the role of social media in California's drought risk management in 2014. J. Nat. Dis. 2015, 79, 171-193. [CrossRef]

12. Rotondi, L.; Zuddas, M.; Marsella, P.; Rosati, P. A Facebook page created soon after the Amatrice earthquake for deaf adults and children, families, and caregivers provides an easy communication tool and social satisfaction in maxi-emergencies. Prehosp. Disaster Med. 2019, 34, 137-141. [CrossRef]

13. Muralidharan, S.; Rasmussen, L.; Patterson, D.; Shin, J.H. Hope for haiti: An analysis of facebook and twitter usage during the earthquake relief efforts. Public Relat. Rev. 2011, 37, 175-177. [CrossRef] 
14. Sutton, J.; Spiro, E.S.; Butts, C.T. Tweeting the spill: Online informal communications, social networks, and conversational microstructures during the deepwater horizon oil spill. Int. Conf. Inf. Sys. Crisis Response Manag. 2013, 5, 58-76. [CrossRef]

15. Tapia, A.H.; Moore, K. Good enough is good enough: Overcoming disaster response organizations' slow social media data adoption. Comput. Supp. Coop. Work 2014, 23, 483-512. [CrossRef]

16. Spence, P.R.; Lachlan, K.; Burke, J.M.; Seeger, M.W. Media Use and Information Needs of the Disabled During a Natural Disaster. J. Health Care Poor Underserved 2019, 18, 394-404. [CrossRef] [PubMed]

17. Jong, W.; Dückers, M.L.A.; Van, D.V.P.G. Crisis leadership by mayors: A qualitative content analysis of newspapers and social media on the MH17 disaster. J. Cont. Crisis Manag. 2016, 24, 286-295. [CrossRef]

18. Landwehr, P.M.; Carley, K.M. Social media in disaster relief: Usage patterns, data mining tools, and current research directions. Data Min. Knowl. Discov. 2014, 1, 225-257.

19. Carley, K.M.; Malik, M.; Landwehr, P.M.; Pfeffer, J.; Kowalchuck, M. Crowd sourcing disaster management: The complex nature of Twitter usage in Padang Indonesia. Saf. Sci. 2016, 90, 48-61. [CrossRef]

20. Lindsay, B.R. Social Media and Disasters: Current uses, Future Options, and Policy Considerations; CRS Report Congress: Washington, DC, USA, 2011; Volume 2, pp. 1-14.

21. Briones, R.L.; Kuch, B.; Liu, B.F.; Jin, Y. Keeping up with the digital age: How the American Red Cross uses social media to build relationships. Public Relat. Rev. 2011, 37, 37-43. [CrossRef]

22. Hjorth, L.; Kim, K.Y. The mourning after: A case study of social media in the 3.11 earthquake disaster in Japan. Telev. New Media 2011, 12, 552-559. [CrossRef]

23. Qu, Y.; Wu, P.F.; Wang, X. Online community response to major disaster: A study of Tianya forum in the 2008 Sichuan earthquake. In Proceeding of the Hawaii International Conference on System Sciences, Washington, DC, USA, 5-8 January 2009; pp. 1-11.

24. Bruns, A.; Stieglitz, S. Quantitative approaches to comparing communication patterns on twitter. J. Technol. Hum. Serv. 2012, 30, 160-185. [CrossRef]

25. Jung, J.Y.; Moro, M. Multi-level functionality of social media in the aftermath of the great east Japan earthquake. Disasters 2014, 38, 123-143. [CrossRef] [PubMed]

26. Yates, C.; Partridge, H. Citizens and social media in times of natural disaster: Exploring information experience. Inf. Res. 2015, 20, 659.

27. Shklovski, I.; Palen, L.; Sutton, J. Finding community through information and communication technology in disaster response. In Proceeding of the Conference on Computer Supported Cooperative Work, San Diego, CA, USA, 8-12 November 2008; pp. 127-136.

28. Denis, L.A.S.; Palen, L. Mastering social media: An analysis of Jefferson County's communications during the 2013 Colorado floods. In Proceedings of the Paper of the Information Systems for Crisis Response and Management Conference (ISCRAM), University Park, PA, USA, 18-21 May 2014.

29. VSMWG \& DHSFRG. Social Media Strategy; Homeland Security: Washington, DC, USA, 2012.

30. Kaptelinin, V.; Nardi, B. Activity Theory in HCI: Fundamentals and Reflections. Synth. Lect. Hum. Cent. Inform. 2012, 5, 179-184. [CrossRef]

31. VSMWG \& DHSFRG. First Responder Communities of Practice Virtual Social Media Working Group Community Engagement Guidance and Best Practices; Department of Homeland Security: Washington, DC, USA, 2012.

32. Shu, M.; Scott, N. Influence of social media on Chinese students' choice of an overseas study destination: An information adoption model perspective. J. Travel Tourism Mark. 2014, 31, 286-302. [CrossRef]

33. David, C.C.; Ong, J.C.; Legara, E.F.T. Tweeting super typhoon Haiyan: Evolving functions of Twitter during and after a disaster event. PLoS ONE 2016, 11. [CrossRef]

34. Qu, Y.; Huang, C.; Zhang, P.; Zhang, J. Microblogging after a major disaster in China: A case study of the 2010 Yushu earthquake. In Proceeding of the 2011 ACM Conference on Computer Supported Cooperative Work, Hangzhou, China, 19-23 March 2011; pp. 25-34.

35. Zydney, J.M.; Hai-Jew, S.; Renninger, K.A.; List, A.; Blumschein, P. Semantic Classification. In Encyclopedia of the Sciences of Learning; Springer: New York, NY, USA, 2012.

36. Chatfield, A.T.; Brajawidagda, U. Crowdsourcing hazardous weather reports from citizens via Twitter sphere under the short warning lead times of EF5 intensity Tornado conditions. In Proceeding of the Hawall International Conference on System Science (HICSS), Washington, DC, USA, 6-9 January 2014; pp. 2231-2241. 
37. Chatfield, A.T.; Brajawidagda, U. Twitter Early Tsunami Warning System: A Case Study in Indonesia's Natural Disaster Management. Hawaii International Conference on System Sciences. 2013. Available online: https://ieeexplore.ieee.org/stamp/stamp.jsp?tp=\&arnumber=6480088 (accessed on 7 May 2019).

38. Fang, J.; Hu, J.; Shi, X.; Zhao, L. Assessing disaster impacts and response using social media data in China: A case study of 2016 Wuhan rainstorm. Int. J. Disaster Risk Reduct. 2019, 34, 275-282. [CrossRef]

39. Anderson, C. The long tail. Wired Mag. Am. 2004, 10, 170-177.

40. Granovetter, M.S. The strength of weak ties. Am. J. Sociol. 1973, 78, 1360-1380. [CrossRef]

41. Guan, W.; Gao, H.; Yang, M.; Yuan, L.; Ma, H.; Qian, W. Analyzing user behavior of the micro-blogging website sina weibo during hot social events. Phys. A 2014, 395, 340-351. [CrossRef]

42. Tang, J.; Folmer, H.; Xue, J. Estimation of awareness and perception of water scarcity among farmers in the guanzhong plain, china, by means of a structural equation model. J. Environ. Manag. 2013, 126, 55-62. [CrossRef]

43. Kongthon, A.; Hareuchaiyasak, C.; Pailai, J.; Kongyoung, S. The role of Twitter during a natural disaster: Case study of 2011 Thai flood. In Proceeding of Technology Management for Emerging Technologies, Vancouver, BC, Canada, 29 July-2 August 2012; pp. 2227-2232.

44. Mersham, G.M. Social media and public information management: The September 2009 tsunami threat to New Zealand. Media Int. Aust. 2010, 32, 130-143. [CrossRef]

45. Schwartz, S.H. A theory of cultural values and some implications for work. Appl. Psychol. 1999, 48, $23-47$. [CrossRef]

46. Chang, L.; Mak, M.C.K.; Li, T.; Wu, B.P.; Chen, B.B.; Lu, H.J. Cultural adaptations to environmental variability: An evolutionary account of east-west differences. Educ. Psychol. Rev. 2011, 23, 99-129. [CrossRef]

47. Sui, J.; Liu, C.H.; Han, S. Cultural difference in neural mechanisms of self-recognition. Soc. Neurosci. 2009, 4, 402-441. [CrossRef] [PubMed]

48. Wang, Z.; Ye, X. Space, time, and situational awareness in natural hazards: A case study of Hurricane Sandy with social media data. Cartogr. Geogr. Inf. Sci. 2019, 46, 334-346. [CrossRef]

49. Gupta, A.; Joshi, A.; Kumaraguru, P. Identifying and characterizing user communities on twitter during crisis events. In Proceeding of the 2012 Workshop on Data Driven User Behavioral Modelling and Mining from Social Media, Maui, HI, USA, 29 October 2012; pp. 23-26.

50. Bevc, C.A.; Simon, M.C.; Montoya, T.A.; Horney, J.A. Institutional facilitators and barriers to local public health preparedness planning for vulnerable and at-risk populations. Public Health Rep. 2014, 129, 35-41. [CrossRef]

51. Bird, D.; Ling, M.; Haynes, K. Flooding Facebook-the use of social media during the Queensland and Victorian floods. Aust. J. Emerg. Manag. 2012, 27, 27-33.

52. Ruiz Sinoga, J.D.; Gross, T.L. Droughts and their social perception in the mass media (southern Spain). Int. J. Climatol. 2013, 33, 709-724. [CrossRef]

53. Wilhite, D.A.; Hayes, M.J.; Knutson, C.; Smith, K.H. Planning for drought: Moving from crisis to risk management. J. Am. Water Resour. Assoc. 2010, 36, 697-710. [CrossRef]

54. Feldman, D.; Contreras, S.; Karlin, B.; Basolo, V.; Luke, A. Communicating flood risk: Looking back and forward at traditional and social media outlets. Int. J. Disaster Risk Reduct. 2015, 15, 43-51. [CrossRef]

(C) 2019 by the authors. Licensee MDPI, Basel, Switzerland. This article is an open access article distributed under the terms and conditions of the Creative Commons Attribution (CC BY) license (http://creativecommons.org/licenses/by/4.0/). 